\title{
A filosofia como dispositivo de transformação na educação
}

Danilo Melo ${ }^{1}$

\section{Resumo}

Este artigo busca pensar como o ensino da filosofia produz processos de transformação nos modos de vida ocasionando experiências de pensamento que ultrapassam o bom senso e o senso comum e problematizam o próprio pensamento no sentido de abri-lo à criação de outros modos de pensar e de agir. A experiência do pensamento deflagrada pelo encontro da filosofia com a educação se desprende um movimento do pensar que afeta a vida de seus ensinantes e aprendentes abrindo-lhes possibilidades de mudanças em seus modos habituais de compreender e se relacionar com a diversidade do mundo, tornando a filosofia um vetor de mutação e uma prática de resistência não apenas dentro, mas também fora da escola.

Palavras-chave: Ensino de filosofia; Experiência do pensamento; Criação.

\begin{abstract}
This article aims to think like the teaching of philosophy produce processes of transformation in lifestyles leading thought experiments that go beyond common sense and common sense and problematize the very thought in order to open it to creation of other ways of thinking and acting. Such questioning of the understanding that the thought experiment gives off a movement of thought that affects the lives of those who practice it, triggering shifts and breaks in the usual ways of understanding and relating to the world and with himself. In this sense, philosophy is been constituted as a vector of mutation and resistance of practice not only within but also outside of school.
\end{abstract}

Keywords: Teaching philosophy; Thought experiment; Creation.

${ }^{1}$ Professor do Departamento de Psicologia da Universidade Federal Fluminense (UFF). 
Introdução

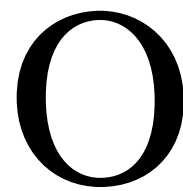

s limites e as possibilidades do ensino de filosofia variam de acordo com as múltiplas formas através das quais a filosofia pode ser entendida e ensinada, seja pelo debate em torno do conjunto da história da filosofia; pela discussão dos métodos e formas de questionamentos que constituem as diversas teorias, escolas, doutrinas e sistemas; pelos problemas que motivam a produção conceitual, seja a partir de temas mais amplos que envolvam a discussão sobre a verdade, o conhecimento, a razão, a lógica, a metafísica, a consciência crítica etc. (Rocha, 2010). Diante deste conjunto de alternativas podemos destacar dois modos gerais de se abordar a filosofia: 1) como teoria ou sistema de pensamento, e 2) como uma prática ou exercício do pensar, como experiência do pensamento. Consideramos que estas duas formas se atravessam e, portanto, não as tomamos como antinômicas ou excludentes. Contudo, compreendemos que a experiência do pensamento desprende um movimento do pensar que afeta a vida de quem a pratica, acionando deslocamentos e rupturas nos modos habituais de compreender e se relacionar com o mundo e consigo mesmo, produzindo uma deriva que comporta um rumo incerto, um destino inesperado ou mesmo um perigo. Neste sentido, estamos de acordo com Gallo (2008) quando diz que “pensar é experimentar o incômodo do desconhecido, do ainda-não pensado e construir algo que nos possibilite enfrentar o problema que nos fez pensar" (p. 118). Dessa forma, pensar deixa de ser sinônimo de saber ou conhecer e passa a se constituir como uma experiência que vai de encontro ao que há de estigmatizado, fixo, pronto, determinável, previsível e repetitivo no próprio pensamento. Assim, pensar consiste numa experimentação cuja efetuação não se limita a reproduzir um modelo, mas antes a fazer nascer o que ainda não existe, em fazer advir o novo, em criar um mundo diferente e, com este, outras possibilidades de vida.

É sobre este ponto que elaboramos a questão que pretendemos perseguir: pode o ensino da filosofia produzir processos de transformação nos modos de vida a partir de experiências de pensamento, ultrapassando o bom 
senso e o senso comum e problematizando o próprio pensamento, abrindo-o ao diferente e à criação de modos outros de agir e de pensar? Assim, se enquanto experiência de abertura do pensamento não sabemos o que pode a filosofia, podemos ao menos compreender que as problematizações que decorrem do seu ensino proporcionam uma espécie de resistência frente às práticas dominantes que seguem o modelo tradicional da lógica escolar e, ao mesmo tempo, inspiram a possibilidade de pensarmos práticas educacionais de transformação e de criação de si, ou melhor, práticas que viabilizem experiências de si e estejam comprometidas com a produção de novos modos de valorar, pensar, sentir e agir, isto é, com a criação de outros modos de vida. Neste sentido, a filosofia se constitui como um vetor de mutação e uma prática de resistência não apenas dentro, mas também fora da escola, já que seu exercício consiste em problematizar tanto os sentidos habituais que nos ligam e nos mantêm adaptados ao mundo que nos rodeia, quanto os valores dominantes da sociedade à qual pertencemos.

\section{O que significa pensar?}

Para compreendermos esta experiência, entretanto, é preciso que definamos o que é o pensamento. A definição nos é inspirada pela filosofia de Gilles Deleuze (1968), cujo esforço se dirige no sentido de desfazer um mal entendido suposto por uma tradição do pensamento filosófico, inaugurada por René Descartes (1992), que insiste em confundir pensar e representar, isto é, em tratar o pensamento como uma capacidade inata ou como o exercício natural de uma faculdade e como se houvesse uma boa vontade do pensamento. Nesta perspectiva, portanto, pensar se confunde com um modo de conhecer ou reconhecer algo representado, ou melhor, é algo que nos coloca diante do conhecido, do sabido ou do verdadeiro: um ato voluntário cuja ação consiste em reproduzir um modelo extraído da generalidade. No entanto, para Gilles Deleuze, essa tendência a enquadrar a experiência que temos do mundo sob a forma da representação ou do já dado se exerce a partir de um modelo que expressa um movimento retroativo sobre a própria experiência. Trata-se do modelo da recognição, cuja tarefa consiste em 
regular o conjunto das nossas percepções, ações, pensamentos e sensações pela realidade instituída socialmente sob a forma de um sistema de convenções que garante um sentimento de familiaridade em relação a tudo o que nos rodeia ou nos é estranho e intolerável.

Na contramão desta perspectiva, Gilles Deleuze (1968) afirma que o pensamento consiste numa experiência que não visa nem ao saber nem ao conhecimento, mas antes à criação do novo e à experimentação, ou seja, à produção da diferença, ao invés da busca pela semelhança ou modelo do Mesmo. Sobre isto Deleuze nos diz:

Pensar não é inato, mas deve ser engendrado no pensamento; [...] o problema não é dirigir, nem aplicar metodicamente um pensamento preexistente por natureza e de direito, mas fazer nascer aquilo que não existe ainda [...]; Pensar, é criar, não há outra criação, mas criar é, antes de tudo, engendrar "pensar" no pensamento (1968, p. 192).

Neste sentido, o pensamento não se confunde com o puro ato da recognição e tampouco se reduz à simples representação, pois a operação que lhe caracteriza supõe a instauração de uma crise na forma do reconhecimento. Afinal, de acordo com Deleuze (1968), “a forma da recognição nunca santificou outra coisa que não o reconhecível e o reconhecido, a forma nunca inspirou outra coisa que não fossem conformidades" (p. 176). Tais conformidades dizem respeito tanto às maneiras de pensar do senso comum e do bom senso, quanto às formas habituais de perceber e sentir que nos ligam confortavelmente às necessidades adaptativas da vida e às exigências utilitárias da sociedade. Sob este aspecto, podemos compreender a importância essencial da atividade recognitiva para a vida orgânica. Entretanto, não podemos confundi-la com o pleno exercício do pensar e aplicá-la de pronto à razão sem o risco de afastar o pensamento de sua atividade singular que consiste em criar mutação nos modos de existência. É o que Deleuze evidencia numa passagem de Diferença e Repetição: 
De um lado, é evidente que os atos de recognição existem e ocupam uma grande parte de nossa vida cotidiana: é uma mesa, é uma maçã, é o pedaço de cera, bom-dia Teeteto. Mas quem pode acreditar que o destino do pensamento se joga aí, e que pensemos quando reconhecemos? (1968, p. 176).

Para Deleuze, desse modo, o pensamento não é sinônimo de representar ou reconhecer e não se faz de forma natural, mas é algo que acontece a partir de um encontro que nos força a pensar. Assim, ele considera que

há no mundo alguma coisa que força a pensar. Este algo é o objeto de um encontro fundamental, e não de uma recognição. O que é encontrado pode ser Sócrates, o templo ou o demônio. Pode ser apreendido sob tonalidades afetivas diversas, admiração, amor, ódio, dor. Mas, em sua primeira característica, e sob qualquer tonalidade, ele só pode ser sentido (1968, p. 182).

Neste sentido, o pensamento não se reduz a uma operação que decorre da razão e do acordo entre as faculdades ditas superiores, mas é acionado por um movimento involuntário que se faz a despeito da vontade de um suposto sujeito pensante. Compreendido desse outro modo, o pensamento expressa antes uma experiência impessoal na medida em que rompe as referências cognitivas que garantem a identidade do eu. Este acontecimento disruptivo nos lança diante do impensável e do imprevisível, e desse modo o pensamento se faz como uma experiência sem qualquer garantia, comportando um rumo incerto e um destino indeterminado quanto aos seus resultados e desenvolvimentos. Portanto, para o filósofo,

só há pensamento involuntário, suscitado, coagido no pensamento, com mais forte razão é absolutamente necessário que ele nasça, por arrombamento, do fortuito no mundo. $\mathrm{O}$ que é primeiro no pensamento é o arrombamento, a violência, é o inimigo, e nada supõe a Filosofia; tudo parte de uma misosofia (Deleuze, 1968, p. 181-182). 
Assim, o pensamento encontra sua condição de efetuação real naquilo que mobiliza nossa capacidade de ser afetado, isto é, supõe um encontro cuja violência esvazia nossas certezas e nos coloca diante da necessidade de criar modos diferentes de nos relacionarmos com o mundo. Trata-se, entretanto, de um encontro com aquilo que nunca foi sentido, percebido, agido, e mesmo pensado, ou seja, com um "signo" ou uma diferença que nos afeta como um imperativo que rompe nosso campo de referências fixas e nos força a procurar um novo sentido, ou melhor, a criar outras maneiras de perceber, agir, pensar e sentir (Deleuze, 1964; 1968).

Nessa experiência, portanto, se estabelece uma crise no conjunto das nossas relações habituais que faz falir todo o sistema de encadeamentos causais (hábitos sensório-motores) de modo que a percepção é cortada de seu prolongamento motor, assim como se rompe o laço habitual que une a ação a uma situação e, por fim, cinde-se o pensamento da representação e a afecção da aderência às formas de sentir bem definidas. $\mathrm{O}$ que o encontro ou o acontecimento viabiliza é a efetuação de uma situação problemática que instaura rachaduras e quebras nos ajustes dos encadeamentos utilitários da vida ordinária dos indivíduos e das sociedades e assim faz emergir as condições de um novo traçado, porém sem que nenhum percurso seja imposto previamente. Assim, nas palavras de Gallo, “o problema nos move a pensar justamente porque não somos capazes de compreendê-lo de antemão; ele não nos oferece uma resposta pronta, mas apresenta-se para nós como um desafio a ser enfrentado, para o qual uma resposta precisa ser construída" (2008, p. 119). Ou seja, diante da experiência ocasionada pelo problema, se abrem para nós as condições de efetuarmos novas conexões e inventarmos combinações que correspondem à criação de outras maneiras de sentir, perceber, pensar e agir, isto é, de avaliar, a nós mesmos e às possibilidades de vida que estamos em vias de devir, e abordarmos a experiência do mundo de uma maneira inédita, para além da forma da recognição.

Experiência do pensamento e criação no ensino de filosofia 
A partir dessas breves considerações acerca dos processos disruptivos acionados pela experiência do pensamento, compreendemos que o ensino de filosofia pode trazer importantes contribuições no que diz respeito ao conjunto dos processos que atravessam a vida daqueles que aí estão implicados. No entanto, é preciso observar qual definição de filosofia estamos aqui pondo em relevo. Como vimos, não se trata de conceber a filosofia como um conjunto de doutrinas e sistemas que constituem o amplo período de sua história. Ensinar filosofia não se limita, nesta perspectiva, a transmitir os aspectos gerais e características de cada filósofo ou corrente filosófica, como um campo de saber muito bem definido objetivamente. Como definir então o que se pretende entender por Filosofia?

Muitos pesquisadores em filosofia da educação, no Brasil e na América Latina, têm reiteradamente adotado a definição que Deleuze e Guattari apresentam em O que é a filosofia? (1991), atribuindo à função ou à tarefa da filosofia a criação de conceitos, em oposição à tradição filosófica que limita sua prática ora a um "refletir sobre”, ora à pura contemplação, ou ao diálogo e à discussão. Estes pesquisadores asseguram que no ensino de filosofia haveria um atravessamento entre o plano de imanência da filosofia com o campo problemático da educação, de modo que deveria resultar daí a invenção de novos conceitos filosóficos referidos aos problemas que a educação portaria em suas práticas e definições ${ }^{2}$.

A partir desta maneira de argumentar a favor da filosofia da educação, fala-se da importância das experiências com crianças e jovens em seu encontro com o ensino de filosofia, das descobertas, dos deslocamentos subjetivos, dos novos problemas inventados ou colocados de uma maneira

\footnotetext{
2 Para citarmos algumas referências importantes, encontramos esta definição da filosofia como criação de conceitos em GALLO (2002; 2005; 2008), em BENETTI $(2005 ; 2007)$ e em HORN \& STANGE (2006). A título de ilustração, pois não é nossa pretensão aprofundar esta questão especificamente neste artigo, deixamos aqui uma citação de Gallo acerca da adoção desta definição e de sua relação com a educação: "Se para a educação é importante a produção conceitual, está justificado seu diálogo com a filosofia. Assim, a filosofia como singularidade de campos de saberes atravessa o platô educação, que por sua vez assume a perspectiva de um 'plano de imanência' do qual podem brotar conceitos filosóficos; [...] podemos compreender a educação como um plano, um corte, a partir do qual conceitos poderão ser criados. Esses conceitos serão, necessariamente, produções ao nível da problemática educativa, dirão respeito aos problemas suscitados pela educação" (2002, p. 285).
} 
inédita etc., porém não vemos nestes relatos a criação de qualquer conceito filosófico.

É preciso, entretanto, compreender a importância que Deleuze atribui à relação da filosofia com o não filosófico, e mesmo quando diz que a filosofia deve ser dirigida para os não filósofos. Na letra "P" (professor) do Abecedário (Boutang \& Parnet, 2004), o próprio Deleuze diz que a partir de um determinado período de sua carreira suas aulas eram constituídas majoritariamente por estudantes das mais diversas áreas que não a filosofia, inclusive por pessoas que não estavam na academia e até mesmo por loucos. Enfim, Deleuze não estabelecia qualquer limite a quem se dirigia às suas aulas, por acreditar que a filosofia, ou melhor, as idéias e problemas filosóficos dizem respeito e poderiam chegar a qualquer um. É a partir desta maneira de conceber a filosofia e a sua relação com o plano mais amplo da realidade e da vida, isto é, com o não-filosófico, que apoiamos nossa perspectiva de análise acerca de seu ensino e buscamos suas possíveis contribuições para aqueles que aí estão implicados.

\section{Conclusão: o que se cria no ensino de filosofia?}

Não deixamos de considerar o fato de Deleuze atribuir à tarefa da filosofia a criação de conceitos, mas aqui fazemos uma distinção entre dois momentos ou duas formas de abordar a filosofia colocadas por ele próprio. O momento em que afirma que a filosofia cria conceitos pretende dar conta daquilo que ele mesmo, enquanto filósofo, fez durante toda a sua vida. Neste âmbito, o trabalho do filósofo é difícil e exige muita dedicação, porém observamos que não é isto o que ocorre nas aulas de filosofia nos níveis fundamental e médio. Não são criados conceitos quando do encontro das crianças e jovens com o ensino de filosofia. Nem mesmo nas universidades os professores de filosofia, e muito menos os seus alunos, estão criando conceitos e realizando a tarefa que Deleuze atribui aos "filósofos". Não criamos conceitos, nem os que ensinam filosofia, nem os que estão ali entrando em contato com o seu ensino.

Com isso, entretanto, não estamos de todo distantes do que diz Deleuze e Guattari em $O$ que é a filosofia?, mas estamos entrando em contato de 
maneira mais próxima com o que é afirmado em outros momentos. Em obras anteriores, sobretudo em Diferença e repetição e Lógica do sentido, Deleuze considera como a singularidade da filosofia o seu aspecto problematizante e criador de novos modos de perceber, sentir e pensar. Aí, sua maneira de abordar a filosofia consiste em compreender nela a potência de desencadear experiências de pensamento que subvertem o modo ordinário de "pensar", o qual equivaleria a um simples reconhecer ou representar.

Penso, desse modo, que o que efetivamente pode se produzir nas aulas de filosofia para crianças e jovens não são conceitos, mas experiências que possibilitam justamente que se escape deste modo representacional e recognitivo de "pensar". O que encontraria ressonâncias com aquilo que Deleuze afirma ao comentar acerca do problema do pensamento para Michel Foucault: “pensar é experimentar, é problematizar" (1986, p. 124). Para Deleuze assim como para Foucault, acionar a experiência do pensamento consiste em produzir deslocamentos nos modos habituais de nos remetermos às coisas e às ideias; e são estes processos disruptivos que, na perspectiva aqui adotada, podem ser deflagrados pelo ensino de filosofia e com os quais nos deparamos quando participamos das aulas ou experiências de filosofia com crianças e jovens nas escolas, e até mesmo com adultos nas universidades.

Com isso, a pretensão aqui está se esboçando afirmar consiste em trazer o nosso olhar para aquilo que efetivamente se produz nas aulas e oficinas de filosofia com jovens e crianças, já que sabemos que não são conceitos que estas práticas geram. Penso ser louvável e mesmo desejável apostarmos que o objetivo e a tarefa do ensino de filosofia seja a criação de conceitos, como aparece em diversos materiais teóricos produzidos em torno da relação entre filosofia e educação, mas não podemos ficar limitados a este plano ideal e mais abstrato sem o risco de nos alienarmos das práticas e contribuições efetivas do ensino de filosofia com crianças e jovens. É importante compreendermos que o fato de que não criemos conceitos nestas práticas não significa que nada se crie nelas, e é para isto que pretendo aqui chamar atenção ao apontar para a necessidade de apreender aquilo que se estende entre a filosofia e o seu fora não-filosófico, isto é, o que permite que o 
conceito filosófico retroaja de maneira crítica e inventiva sobre os aspectos mais diversos da realidade e da vida.

Partamos então deste campo mais amplo da realidade e da vida humanas, nele os problemas, colocados ou impostos, não deixam de se fazer presentes, e diante deles responde-se de diversas maneiras: seja, por exemplo, pela produção de um deslocamento subjetivo, ou mesmo pela invenção de um objeto ou de um recurso técnico, e até mesmo quando não os suportamos e nos esforçamos em negá-los mobilizamos nossas forças. É, portanto, sobre este âmbito mais amplo da vida e da realidade que a noção de problema remete à filosofia de Deleuze através da noção de encontro e do conceito de acontecimento e nos permite assim apreender a passagem que liga o filosófico com o não-fílosófico.

Em Lógica do sentido (1969), Deleuze afirma que "os acontecimentos concernem exclusivamente aos problemas", que "o acontecimento é por si mesmo problemático e problematizante" (p. 57) e por isso mesmo nos forçam a pensar, isto é, a nos colocar numa disposição diferente diante do mundo dos eventos, ao demandar a criação de novos sentidos diante da falência e da inadequação dos nossos modos habituais de pensar, perceber, sentir e agir no mundo. Contudo, para que se efetue o ato de criação de outros modos de vida e se afirme uma nova disposição sensível face ao mundo, é preciso que se queira alguma coisa a vir de conformidade ao que acontece, isto é, "tornar-se digno daquilo que nos acontece, então aí querer e capturar o acontecimento, tornar-se o filho de seus próprios acontecimentos, e por aí renascer, refazer para si mesmo um nascimento, romper com seu nascimento de carne" (Deleuze, 1969, p. 175). Nesta operação, ao invés de reagirmos ao mundo negando o que os acontecimentos trazem de problemático, passamos a estabelecer com eles uma relação ativa e positiva na qual afirmamos no que acontece aquilo que permite deslocar nossos sentidos habituais e criarmos novas maneiras de pensar, sentir e se relacionar com o mundo.

Com isso, continuamos ainda próximos do que nos diz Deleuze se ficarmos com a ideia de que a filosofia, antes de e para criar conceitos, tem 
por singularidade a tarefa de criar problemas $^{3}$. Portanto a filosofia começa por problematizar o próprio pensamento naquilo que ele tem de estigmatizado, determinado, previsível, repetitivo e representado, isto é, naquilo que o mantém preso ao modelo recognitivo. Enquanto dispositivo de problematização, a filosofia se coloca na contramão de toda forma de pensamento que busca soluções confortadoras ao espírito, estando antes engajada na tarefa de formar o espírito crítico e problematizador e forçar o acionamento da capacidade criadora de novos sentidos para o pensamento. É neste sentido que, a partir das experiências de filosofia com crianças e jovens nas escolas, e mesmo da experiência em sala de aula com jovens e adultos na universidade, pretendemos afirmar que a filosofia se apresenta como um potente dispositivo de transformação dos modos de pensar, compreender e perceber a realidade daqueles que participam de seu ensino.

Nisto a filosofia expressa sua grandeza quando do seu encontro com os não-filósofos, os quais não lhe retribuirão com conceitos, mas encontrarão nela a condição de transformarem seus modos de vida. Transformar seus modos de vida não significa, entretanto, produzir um deslocamento vertical ou evolutivo, mas antes uma abertura de horizontes e uma expansão na sua capacidade de se relacionar com o mundo, produzindo um alargamento das noções limitadas e limitadoras assimiladas passivamente na experiência do senso comum e do bom senso.

Neste sentido, não é pequena a contribuição que a filosofia viabiliza aos que participam de seu ensino, já que as situações problematizantes que derivam daí nos lançam numa experiência em que somos forçados a pensar e a criar outros modos de relação com o mundo. Os problemas, no entanto, não sendo uma propriedade da filosofia e ao não se limitarem ao seu campo próprio enquanto disciplina de ensino, podem ser deflagrados a partir de encontros nos mais diversos contextos e com as mais diversas matérias. Eles

\footnotetext{
${ }^{3}$ É preciso compreender que para Deleuze os conceitos que um filósofo cria estão remetidos aos problemas que ele coloca, ou seja, a condição da criação de conceitos pelo filósofo é a problematização. Mas a colocação de problemas não se restringe aos filósofos de profissão, e pode ser feita por qualquer um. Um cientista e mesmo um artista colocam problemas, e estes são respondidos não através de conceitos, mas por proposições e compostos de sensações, respectivamente (Deleuze \& Guattari, 1992).
} 
podem irromper no encontro com as artes plásticas, com a literatura, com a poesia, com a política, com o cinema, com os próprios conceitos filosóficos, nas oficinas de pensamento com crianças nas escolas, não se restringindo ao uso de elementos propriamente filosóficos, porém ligados à filosofia justamente por seu aspecto problematizante. É, por fim, a partir da possível irrupção de uma experiência do pensamento deflagrada pelo encontro da filosofia com o não-filosófico na educação que acreditamos encontrar a potência de seu ensino ao afetar seus ensinantes e aprendentes, jovens, crianças e adultos, e abrir-lhes possibilidades de mudanças em seus modos habituais de compreenderem e se relacionarem com a diversidade do mundo.

\section{Referências Bibliográficas}

BENETTI, Cláudia C. "Dificuldades e possibilidades que constituem o processo de ensino aprendizagem de filosofia nas escolas: um olhar voltado às implicações singulares na constituição do pensamento”. In: RIBAS, M. A. C. et al. (orgs.). Filosofia e ensino: a filosofia na escola. Ijuí: Ed. Unijuí, 2005.

. "Ensinar a pensar no contexto do ensino de filosofia: um estudo com Gilles Deleuze”. In: SARDI, S. A.; SOUZA, D. G. de; \& CARBONARA, V. (orgs.). Filosofia e sociedade: perspectivas para o ensino de filosofia. Ijuí: Ed. Unijuí, 2007. BOUTANG, Pierre-André \& PARNET, Claire. L'Abécédaire de Gilles Deleuze (3DVDs). Paris: Les Éditions Montparnasse, 2004.

DELEUZE, Gilles. Proust et les signes. Presses Universitaires de France, Paris, 1964.

Différence et répétition. Presses Universitaires de France, Paris, 1968.

. Logique du sens. Les Éditions de Minuit, Paris, 1969.

. Foucault. Les Éditions de Minuit, Paris, 1986

DELEUZE, Gilles ; GUATTARI, Felix. Qu'est-ce que la philosophie? Les Éditions de Minuit, Paris, 1991.

DESCARTES, René. Méditatios métaphysiques. Paris: Garnier-Flammarion, 1992.

GALLO, Sílvio. "Filosofia e Educação: pistas para um diálogo transversal”. In: KOHAN, Walter O. (org.). Ensino de Filosofia - perspectivas. Belo Horizonte: Autêntica, 2002. 
"Filosofia na educação básica: uma propedêutica à paciência do conceito". In: RIBAS, M. A. C. et al. (orgs.). Filosofia e ensino: a filosofia na escola. Ijuí: Ed. Unijuí, 2005.

- "O problema e a experiência do pensamento: implicações para o ensino da filosofia". In: BORBA, Siomara \& KOHAN, Walter O. (orgs.). Filosofia, aprendiragem, experiência. Belo Horizonte: Autêntica, 2008.

HORN Geraldo B. \& STANGER, Fábio. "A Filosofia como criação de conceitos: a questão da especificidade da produção do saber filosófico”. In: MAAMARI, A. M.; BAIRROS, A. T. C. de; \& WEBER, J. F. (orgs.). Filosofia na universidade. Ijuí: Ed. Unijuí, 2006.

ROCHA, Ronai P. da. "Ensino de Filosofia e sensibilidade à ocasião". In: NOVAES, José L. C. (org.). Filosofia e seu ensino: desafios emergentes. Porto Alegre: Sulina, 2010. 